\title{
Progress in Research on Small Molecules as Gene-targeted Drugs
}

\author{
Yanli WANG \\ Lab of Chemical Biology and Molecular Drug Design, \\ College of Pharmaceutical Science \\ Zhejiang University of Technology \\ Hangzhou, China \\ e-mail: ylwang@zjut.edu.cn
}

\section{Jun XU}

College of Pharmaceutical Science

Zhejiang University of Technology

Hangzhou, China

e-mail:243217667@qq.com

\author{
Sijia WANG \\ Lab of Chemical Biology and Molecular Drug Design, \\ College of Pharmaceutical Science \\ Zhejiang University of Technology \\ Hangzhou, China \\ e-mail: 905520666@qq.com \\ Wen ZHANG* \\ Lab of Chemical Biology and Molecular Drug Design, \\ College of Pharmaceutical Science \\ Zhejiang University of Technology \\ Hangzhou, China \\ e-mail: wzhang63@zjut.edu.cn
}

\begin{abstract}
The findings of effective targets and the identification of target binding molecules are two key points in drug discovery. The complete human genome and their rapid increase in structural and functional information led to new possibilities for diagnosis and therapy of diseases, using genetargeted drugs. Currently, gene-targeted drugs includes groove binders, intercalators, alkylators and cleavage agents and are widely used in cancer, Alzheimer's disease, blood pressure, heart and autoimmune diseases research and therapy. A review on the targeted genes, their interaction molecules and the application on disease therapy is presented.
\end{abstract}

Keywords-gene-targeted drug; G-quadruplex; polyamide

\section{INTRODUCTION}

Understanding sequence, function and structure of target genes is very important for discovery of a gene-targeted drug. Based on the complete human genome data, the next challenge in human health research is to interpret the underlying mechanisms of complex diseases. Great effort has been spent on finding the genes associated to diseases. DisGeNET is a discovery platform integrating information on gene-disease associations from several public data sources and the literature (Fig.1) [1], which contains 381056 associations, between 16666 genes and 13172 diseases. Other gene databases such as LOVD databases (for hereditary breast cancer and colorectal cancer genes) [2], MutationView/KMcancerDB database (for cancer gene mutations) [3], Candidate Cancer Gene Database (for cancer driver genes) [4] are also available. A systematic search and in-depth study of each gene and their mechanistic aspects of the diseases has the potential to become a crucial component of medical research.

DNA/RNA sequences can form tertiary structures including double helix, triple helix or G-quadruplex with a large variety of topologies. Among them, B-DNA and Gquadruplex (DNA/RNA) are key targets for most gene- targeted drugs, for their key functions in cellular processes. Especially recently years G-quadruplexes have been found in important guanine-rich regions of the human genome, such as oncogene promoters and telomeres [5, 6]. Gquadruplex structures are highly flexibility and polymorphic [5]. The unimolecular G-quadruplex can theoretically adopt 26 folding topologies (Fig. 2) [7]. The structural polymorph and dynamic equilibrium of G-quadruplexes appear to be intrinsic to the highly conserved sequence and may be the challenge for G-quadruplexes targeted drug design [7].

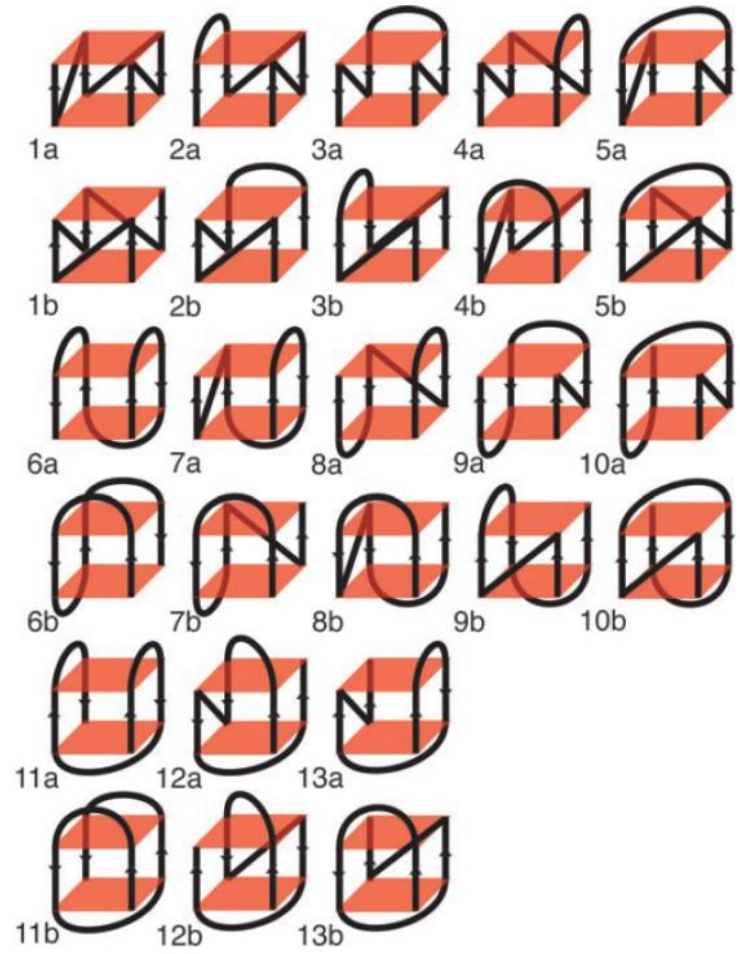

Figure 2. 26 topologies of unimolecular G-quadruplex [7] 


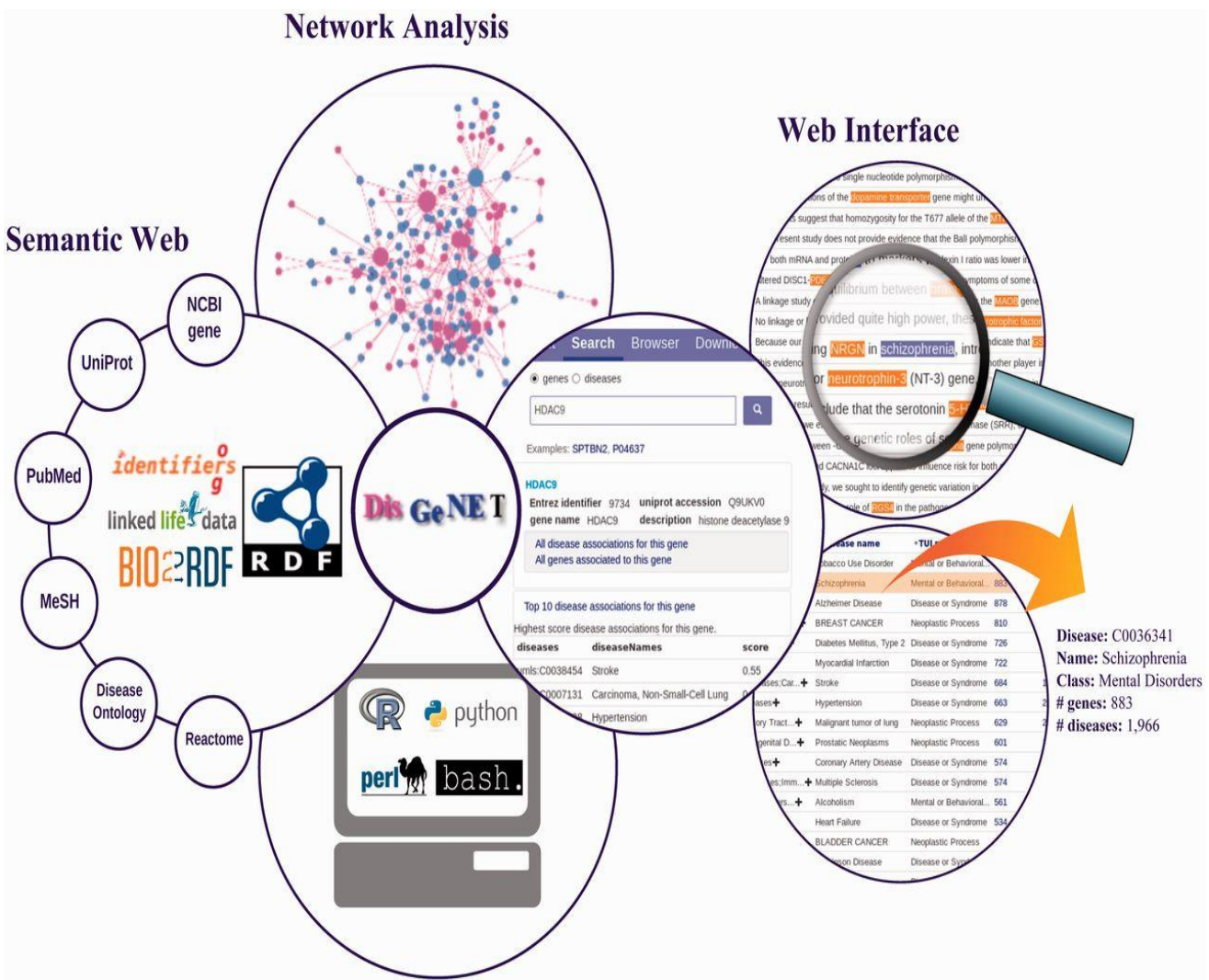

Programmatic Access

Figure 1. The main features of the DisGeNET discovery platform [1]

\section{RESULTS AND DISCUSSION}

\section{A. Interactions between Target Genes and Small Molecules}

Small molecules may interact or bind with DNA/RNA in different ways: binding in the minor groove; intercalation between base pairs and alkylation and cleavage of DNA/RNA.

Among DNA/RNA binders, polyamides are a class of DNA minor groove binders made up of N-methylpyrrole (Py) and N-methylimidazole (Im) that can bind to DNA in a sequence-specific manner [8]. An $\mathrm{Im} / \mathrm{Py}$ recognizes and binds to $\mathrm{G}: \mathrm{C}$ from $\mathrm{C}: \mathrm{G}$, whereas a $\mathrm{Py} / \mathrm{Im}$ recognizes and binds to C:G. A Py/Py pair degenerately binds to T:A or A:T, whereas a hydroxypyrrole (Hp) opposite a Py recognizes and binds to T:A from A:T, and vice versa. Up to now, polyamides are most reliable class of molecules that can be rationally designed to target desired DNA sequences. The key points in polyamides design include: (1) cellular uptaking; (2) distinguishing T:A from A:T. Our group had made some progress in polyamides structure modifications [9-11].

Intercalators [12] are certain flat aromatic or heteroaromatic molecules (such as acridines) that can slide between the base pairs of ds-DNA (intercalate) or/and stack on the end of G-quadruplex and stabilize the duplex or/and quadruplex. Intercalation on ds-DNA has the effect of lengthening the duplex by around $3 \AA$ per bound drug molecule, causes unwinding of DNA, and prevents replication and transcription by interfering with the action of topoisomerases. Some intercalators that induce and stabilize the G-quadruplex structure formation can inhibit telomerase in the cancer cell lines or regulate oncogene transcription. The main problems in G-quadruplex stabilizer research is the highly flexibility and polymorphy of the target. Our group had designed and synthesized a novel benzo[k,1]thioxanthene compounds which were approved with abilities to induce the formation of and stabilize the telomeric antiparallel G-quadruplex, and consequently inhibit telomerase activity, leading to cell apoptosis, can be screened for the discovery of novel antitumor drugs.

Alkylators [13] are strongly electrophilic compounds that react covalently with DNA bases. The resulting DNA adducts are irreversible inhibitors of gene transcription and translation. The DNA-cleaving agents [14] can generate reactive radicals that produce cleavage of the polynucleotide strands. Many alkylating and cleaving agents are mutagenic and/or carcinogenic, and also can react with other biomolecules, resulting in some side effects. For example, Fig. 3 presents interactions of small molecules with target genes and by molecular simulation technique $[15,16]$. 
A.

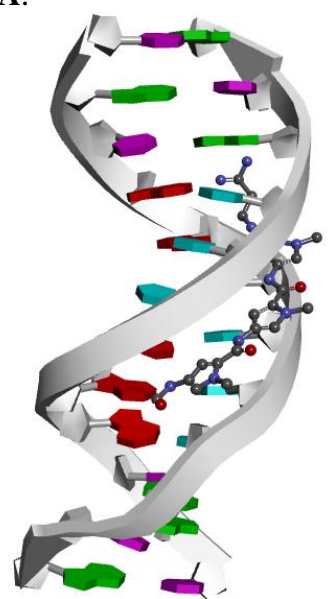

B.

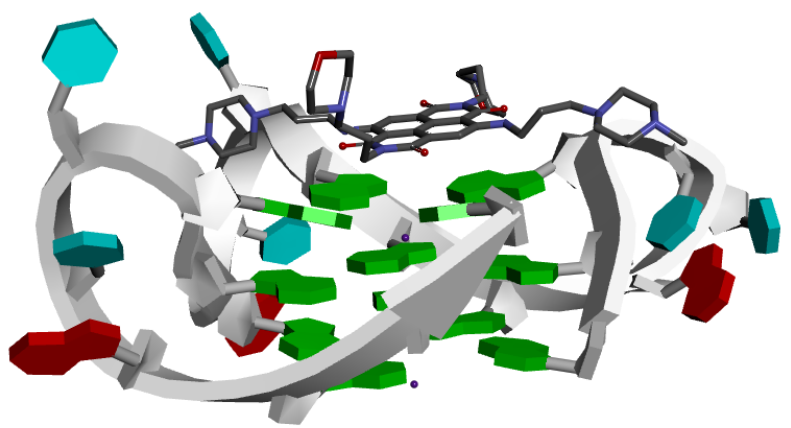

Figure 3. Interactions between target genes and small molecules (A: DNA dodecamer d(CGCAAATTTGCG) complex with distamycin (PDB: 2DND) [15]; B: 21mer DNA G-quadruplex complex with naphthalene diimide (PDB: 4DA3) [16]).

\section{B. FDA Approved Drugs Targeting DNA/RNA}

Some FDA approved drugs that target DNA/RNA are listed in Table I [17], of which the most important one is called either adriamycin or doxorubicin. Mitomycin is activated in liver cells and adds an alkyl group to bases, causing DNA to cross-link, which kills the cancer cells. Another alkylating agent, Ifosfamide, is used to treat testicular cancer, breast cancer, lymphoma, cervical cancer, bone cancer, soft tissue sarcoma, osteogenic sarcoma, and ovarian cancer. Carboplatin (ParaplatinTM) is a chemotherapeutic agent for treating cancer. Bleomycin (BlenoxaneTM) is a member of a family of glycopeptide antibiotics produced by Streptomyces verticillus. It damages deoxyribose in DNA, causing the strand to break. It is used to treat testicular cancer, along with head and neck cancer.

TABLE I. Some FDA APPRoved DRUgS That TARget DNA/RNA [17].

\begin{tabular}{|c|c|c|}
\hline Targets & Interaction Mode & Drug Name \\
\hline DNA and RNA & Alkylation & $\begin{array}{c}\text { Chlorambucil, Cyclophosphamide, Dacarbazine, Mitomycin, } \\
\text { Ifosfamide }\end{array}$ \\
\hline & Complexation & Cisplatin, Carboplatin \\
\hline & Intercalation & Doxorubicin \\
\hline & Oxidative degradation & Bleomycin \\
\hline RNA & Strand breaks & Aminoglycoside antiinfectives \\
\hline & Interaction with 16S-rRNA & Macrolide antiinfectives \\
\hline & $\begin{array}{r}\text { Interaction with 23S-rRNA } \\
\text { 23S-rRNA/tRNA/2-polypeptide } \\
\end{array}$ & Oxazolidinone antiinfectives \\
\hline
\end{tabular}

\section{Our Works on Gene-Targeted Drug Discovery}

Our group had concentrate on discovering novel genetargeted molecules including polyamides (Fig. 4) which binded to ds-DNA in the minor groove [9-11, 18-22], and novel benzo[k,1]thioxanthene-3,4-dicarboximides (Fig. 5) which induced and stabilized G-quadreplux [23, 24]. The steric configuration of $\alpha$-substituents in the $\gamma$-turns of four polyamides could lead to alteration of their binding properties to different DNA base pairs at the turn position relative to unmodified $\gamma$-turns. The polyamide with a chiral hydroxyl $\gamma$-turn unit favorably bound to T:A over A:T with a relatively high 25 -fold increase in specificity, while the polyamide with the a chiral amino $\gamma$-turn unit has a moderate selectivity in discriminating T:A from A:T.

Furthermore, the novel benzothioxanthene derivatives S1-S6 discovered in our lab displayed differentially abilities to induce the 26nt oligonucleotides to form and to stabilize the G-quadruplex structure with high affinity and selectivity for G-rich DNA vs C-rich DNA, mutated DNA and ds- 
DNA, and to promote apoptosis and inhibit mobility and telomerase activity of A549 cells and SGC-7901 cells, especially compounds S1, S3, S4. S3 was the most optimal one with the maximum $\Delta T m$ value $\left(29.8{ }^{\circ} \mathrm{C}\right)$, and $\mathrm{IC}_{50}$ values (0.60 and $0.53 \mu \mathrm{M}$ for A549 cells and SGC-7901 cells, respectively) and maximum inhibitory rate (94.1\% and
97.2\% for A549 cells and SGC-7901 cells, respectively). This type of compounds can induce and stabilize the Gquadruplex, and consequently inhibit telomerase activity, leading to cell apoptosis, can be screened for the discovery of novel antitumor drugs. Further study on them as target drugs is ongoing.
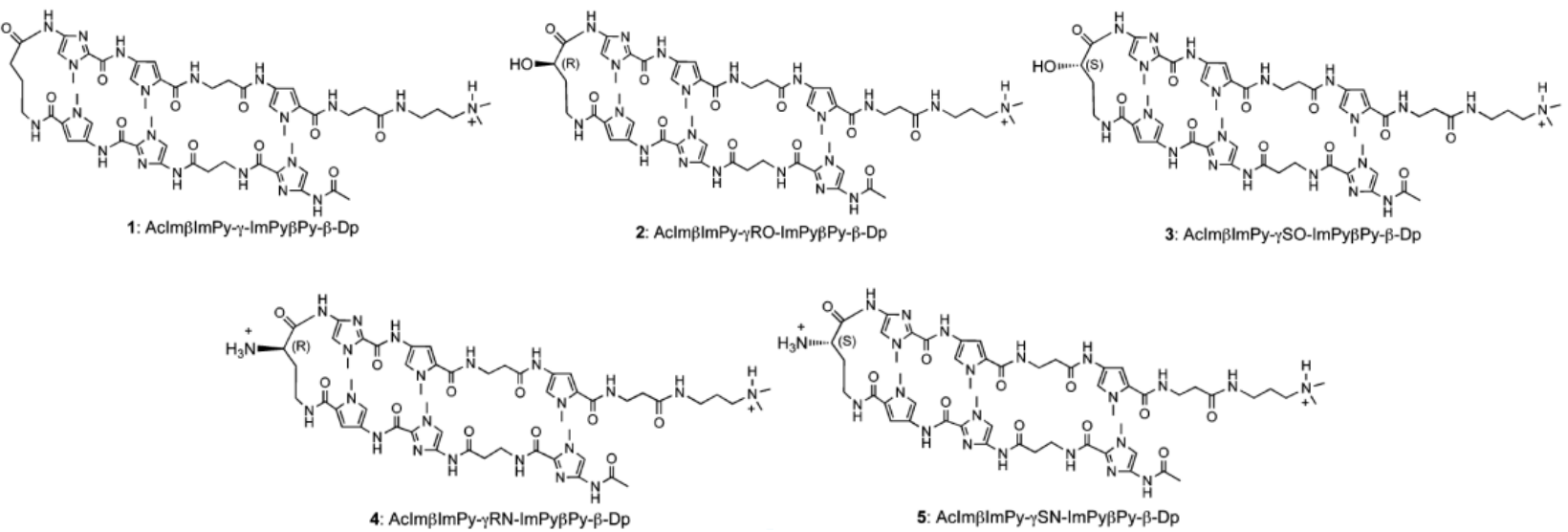

Figure 4. $\alpha$-Substituted $\gamma$-turn of Pyrrole/Imidazole hairpin polyamides.

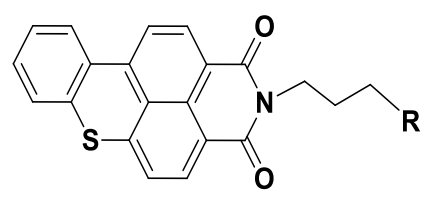

S1-S6

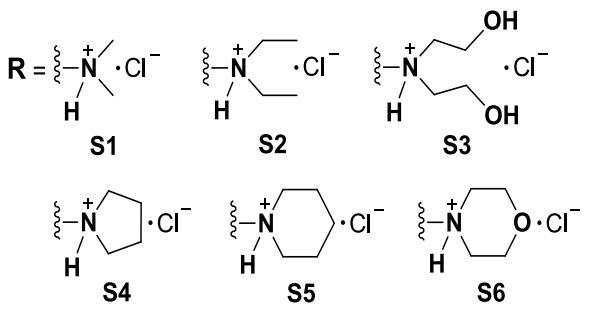

Figure 5. Six novel benzo[k,1]thioxanthene-3,4-dicarboximides (S1-S6).

\section{CONCLUSION}

The last decade has witnessed an exponential growth of sequence, function and structure information in the field of nucleic acids including non-coding RNA, G-quadruplex (RNA/DNA), and their interactions with other molecules. New targeting gene and mechanism discovery will promote the development of targeted drugs of various diseases. With rapid advances in the area, there will be a growing concentration on developing efficient molecules targeting these gene structures with important functions and also the process from gene to drugs will greatly be speeded up. This paper briefly presents the current progress on drug discovery research targeting functionalized important genes and our efforts on this field.

\section{ACKNOWLEDGMENT}

The work was supported by National Natural Science Foundation of China (21572207) and China Postdoctoral Science Foundation (2015M580523).

\section{REFERENCES}

[1] J. Pinero, N. Queralt-Rosinach, A. Bravo, J. Deu-Pons, A. Bauer-Mehren, M. Baron, F. Sanz, And L.I. Furlong, "Disgenet: A Discovery Platform For The Dynamical Exploration Of Human Diseases And Their Genes," Database (Oxford) 2015, 2015.

[2] J. L. Elson, M. G. Sweeney, V. Procaccio, J. W. Yarham, A. Salas, Q. P. Kong, F. H. Van Der Westhuizen, R. D. Pitceathly, D. R Thorburn, M. T. Lott, D. C. Wallace, R. W. Taylor, And R. Mcfarland, "Toward A Mtdna Locus-Specific Mutation Database Using The Lovd Platform," Hum. Mutat., Vol. 33, Pp. 1352-1358, 2012.

[3] N. Shimizu, M. Ohtsubo, And S. Minoshima, "Mutationview/Kmcancerdb: A Database For Cancer Gene Mutations," Cancer Sci., Vol. 98, Pp. 259-267, 2007.

[4] K. L. Abbott, E. T. Nyre, J. Abrahante, Y. Y. Ho, R. Isaksson Vogel, And T. K. Starr, "The Candidate Cancer Gene Database: A Database Of Cancer Driver Genes From Forward Genetic Screens In Mice," Nucleic Acids Res., Vol. 43, Pp. D844-848, 2015.

[5] J. Dai, M. Carver, And D. Yang, "Polymorphism Of Human Telomeric Quadruplex Structures," Biochimie, Vol. 90, Pp. 11721183,2008

[6] S. M. Haider, G. N. Parkinson, And S. Neidle, "Structure Of A GQuadruplex-Ligand Complex," J. Mol. Biol., Vol. 326, Pp. 117-125, 2003

[7] M. Webba Da Silva, "Geometric Formalism For Dna Quadruplex Folding," Chemistry, Vol. 13, Pp. 9738-9745, 2007.

[8] P. B. Dervan And B. S. Edelson, "Recognition Of The Dna Minor Groove By Pyrrole-Imidazole Polyamides," Curr. Opin. Struct. Biol., Vol. 13, Pp. 284-299, 2003.

[9] W. Zhang, T. Bando, And H. Sugiyama, "Discrimination Of Hairpin Polyamides With An Alpha-Substituted-Gamma-Aminobutyric Acid As A 5'-Tg-3' Reader In Dna Minor Groove," J. Am. Chem. Soc., Vol. 128, Pp. 8766-8776, 2006.

[10] W. Zhang, S. K. Jiang, Y. L. Wu, C. X. Guo, H. F. Zhang, H. Sugiyama, And X. L. Chen, "Discrimination Between T/A And A/T Base Pairs Of Pyrrole-Imidazole Polyamides Substituted With Chiral Beta-Hydroxy-Gamma-Aminobutyric Acid/Beta-Alanine Pairs," Chembiochem, Vol. 13, Pp. 47-50, 2012.

[11] W. Zhang, M. Minoshima, And H. Sugiyama, "Base Pair Recognition 
Of The Stereochemically Alpha-Substituted Gamma-Turn Of Pyrrole/Imidazole Hairpin Polyamides," J. Am. Chem. Soc., Vol. 128, Pp. 14905-14912, 2006.

[12] N. J. Wheate, C. R. Brodie, J. G. Collins, S. Kemp, And J. R. AldrichWright, "Dna Intercalators In Cancer Therapy: Organic And Inorganic Drugs And Their Spectroscopic Tools Of Analysis," Mini Rev. Med. Chem., Vol. 7, Pp. 627-648, 2007.

[13] J. S. Mccune And J. T. Slattery, "Pharmacological Considerations Of Primary Alkylators," Cancer Treat. Res. Vol. 112, Pp. 323-345, 2002.

[14] L. F. Povirk, "Dna Damage And Mutagenesis By Radiomimetic DnaCleaving Agents: Bleomycin, Neocarzinostatin And Other Enediynes," Mutat. Res., Vol. 355, Pp. 71-89, 1996.

[15] M. Coll, C. A. Frederick, A. H. Wang, And A. Rich, "A Bifurcated Hydrogen-Bonded Conformation In The D(A.T) Base Pairs Of The Dna Dodecamer D(Cgcaaatttgcg) And Its Complex With Distamycin," Proc. Natl. Acad. Sci. Usa, Vol. 84, Pp. 8385-8389, 1987.

[16] M. Micco, G. W. Collie, A. G. Dale, S. A. Ohnmacht, I. Pazitna, M. Gunaratnam, A. P. Reszka, And S. Neidle, "Structure-Based Design And Evaluation Of Naphthalene Diimide G-Quadruplex Ligands As Telomere Targeting Agents In Pancreatic Cancer Cells," J. Med. Chem., Vol. 56, Pp. 2959-2974, 2013.

[17] P. Imming, C. Sinning, And A. Meyer, "Drugs, Their Targets And The Nature And Number Of Drug Targets," Nat. Rev. Drug Discov. Vol. 5, Pp. 821-834, 2006.
[18] H. Yu, Y. L. Wang, X. Y. Zhao, W. Zhang, "Synthetic Small Molecules Targeting G-Quadruplexes And Their Application," Adv. Mat. Res., Vol. 1088, Pp. 507-513, 2015.

[19] Z. J. Li, Y. P. Ding, Y. L. Wu And W. Zhang, "Small Natural Molecules Targeting Dna G-Quadruplexes," Adv. Mat. Res., Vol. 955-959, Pp. 423-426, 2014.

[20] B. J. Chen, Y. L. Wu And W. Zhang, "Small Molecules Targeting Oncogene C-Myc: A Promising Antitumor Therapeutic Strategy," Int. J. Boil. Sci., Vol. 10(10), Pp. 1084-1096, 2014.

[21] Y. L. Wu, G. N. Pandian, Y. P. Ding, W. Zhang, Y. Tanaka And H. Sugiyama, "Clinical Grade Ips Cells: Need For Versatile Smal Molecules And Optimal Cell Sources," Chem. Biol., Vol. 20(11), Pp. 1311-1322, 2013.

[22] J. Liang, Y. L. Wu, W. Zhang, Yoshimasa Tanaka, And Hiroshi Sugiyama. "The C-Kit Receptor-Mediated Signal Transduction And Tumor-Related Diseases," Int. J. Biol. Sci., Vol. 9(5), Pp. 435-443, 2013.

[23] S. Zhang, Y. Wu, And W. Zhang, "G-Quadruplex Structures And Their Interaction Diversity With Ligands," Chemmedchem, Vol. 9, Pp. 899-911, 2014.

[24] W. Zhang, M. Chen, Y. L. Wu, Y. Tanaka, Y. J. Ji, S. L. Zhang, C. H. Wei And Y. Xu, "Formation And Stabilization Of The Telomeric Antiparallel G-Quadruplex And Inhibition Of Telomerase By Novel Benzothioxanthene Derivatives With Anti-Tumor Activity," Sci. Rep., Vol. 5:13693, Pp. 1-14, 2015. 